\title{
Monitoring and mapping landslide displacements: a combined DGPS-stereophotogrammetric approach for detailed short- and long-term rate estimates
}

\author{
A. Demoulin \\ Research Associate NFSR, University of Liège, Liège, Belgium
}

\begin{abstract}
Although desirable for a reliable hazard assessment, rate estimates of landslide motion rarely combine a good time resolution and a sufficiently long time of observation. Here, both angles are tackled for the Manaihan landslide (East Belgium), dramatically reactivated in September 1998. I monitored the landslide displacements by repeated Global Positioning System (GPS) surveys from 1999 to 2005. Two digital elevation models were also produced, one of the landslide topography in 1999 by GPS and a second by stereophotogrammetry from aerial photographs of 1953. Subtracting one model from the other, I mapped the height
\end{abstract}

changes within the landslide over the 1953-1999 period. All measurements consistently showed that, beyond the sudden $\sim 1.5 \mathrm{~m}$ slip of September 1998, the landslide moved at a mean rate of c. $20 \mathrm{~cm} \mathrm{yr}^{-1}$ since 1980 . Most displacements occurred around the winter's end, when long-lasting precipitation combined with minimal evaporation and occasional intense daily rainfall. The motions are spatially determined by seepage from a broken sewage pipe inducing local high pore pressures.

Terra Nova, 18, 290-298, 2006

\section{Introduction}

It is now a common practice to monitor landslide displacements by Global Positioning System (GPS) (Gili et al., 2000; Moss, 2000; Malet et al., 2002; Coe et al., 2003; Squarzoni et al., 2005). With respect to conventional techniques, this approach has proved efficient in depicting small ground displacements in 3D. Moreover, GPS may be used in many more environmental settings than SAR (synthetic aperture radar) interferometry, which is very sensitive to factors such as orientation of the features of interest and loss of coherence due to changes in the ground surface state (Berardino et al., 2003; Squarzoni et al., 2003). However, GPS data sets involving many surveys of a dense network of marks to provide a detailed time evolution of the mass movements remain rare. Moreover, such studies generally encompass only a few-year-interval, thus providing poor information on longer-term landslide kinematics. Historical displacement data may be obtained from the stereophotogram-

Correspondence: Dr Alain Demoulin, Research Associate NFSR, Department of Physical Geography and Quaternary, University of Liège, Sart Tilman, B11, B-4000 Liège, Belgium. Tel.: 324366 5660; fax: 32 4366 5722; e-mail: ademoulin@ulg.ac.be metric analysis of aerial photographs, a method pioneered by Chandler and Brunsden (1995) and recently much used (e.g. Kerle, 2002; Hapke, 2005; Lantuit and Pollard, 2005). Here, I first perform multiple surveying of a 44-point network covering the whole landslide, with more frequent measurements during the winter semester when most displacements occur. Then, I combine the obtained shortterm motion rate with a decadal rate estimated from the comparison of digital elevation models (DEM) of the landslide topography at a 46-year interval, produced either by GPS or stereophotogrammetric techniques. This eventually provide a refined picture of the landslide kinematics which strongly constrains the search for the causes and the factors of landsliding.

\section{Geological and geomorphological setting}

The Manaihan landslide is one of several ancient large landslides extending over the slopes of the main ridges of the moderately dissected Herve tableland, in the Battice area of East Belgium (Demoulin et al., 2003) (Fig. 1). It was dramatically reactivated by heavy rainfall on 14 September 1998, which caused a downslope displacement of several metres and created a 1-m-high scarp at the top of the old headscarp.
Since then, the slide moves down slowly.

The Manaihan landslide is located on the gently sloping $\left(\sim 4^{\circ}\right)$ eastern flank of a S-striking ridge of the Herve tableland, where it extends over 6.8 ha (width $=400 \mathrm{~m} ; \quad$ length $=250 \mathrm{~m}$; Fig. 2) of meadows at $290 \mathrm{~m}$ altitude. The slipped mass has filled the bottom of a small valley, close to the latter's head, and is being now faintly incised in its downstream part. A row of houses are present along its headscarp (Fig. 2B). A water tower is also located less than $50 \mathrm{~m}$ from the scarp and a sewage pipe passes through the landslide.

The ridge, on which the landslide is located, exposes subhorizontal upper Cretaceous strata unconformably resting on the upper Carboniferous shales of the basement (Fig. 1). The landslide, a rotational mudslide with a typical 0.19 depth-to-length ratio of the surface of rupture (Skempton and Hutchinson, 1969), is carved into the Cretaceous Vaals clays which are $12 \mathrm{~m}$ thick and form the bulk of the ridge in this place. The clays are underlain by $4 \mathrm{~m}$ of liquefactionprone fine sands of the Aachen Formation. The basal shear surface of the landslide is located at the Aachen sands-Palaeozoic shales contact (Demoulin and Glade, 2004).

With regard to hydrology, the main aquifer of the Herve tableland lies 


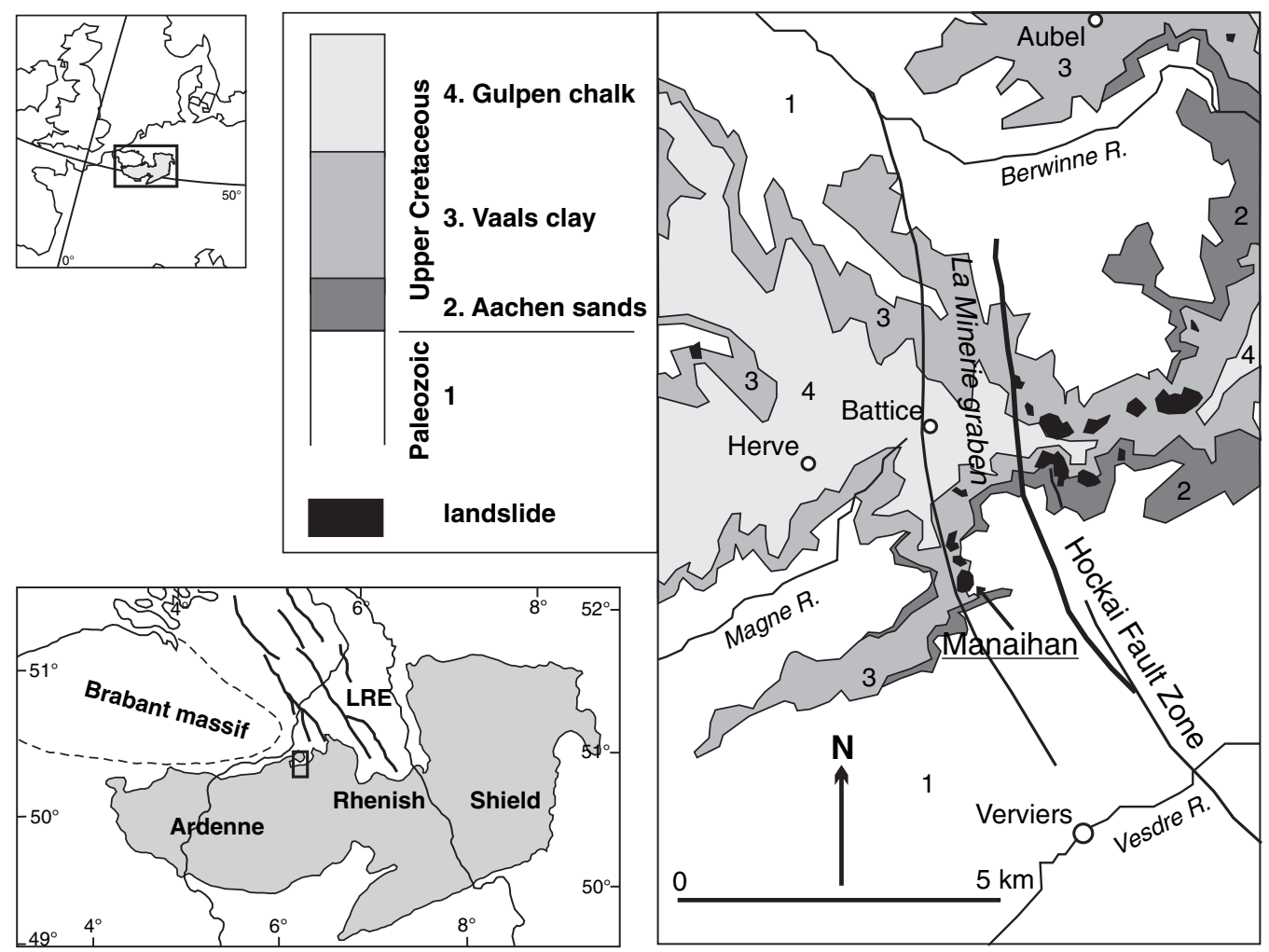

Fig. 1 Geological sketch map with location of the Manaihan and other landslides in the Herve tableland. 1. Palaeozoic basement. 2-4. Upper Cretaceous Formations. The western border fault of the small La Minerie graben follows the strike of the ridge on which the Manaihan landslide is located. Lower left inset: LRE: Lower Rhine Embayment.

within the Gulpen chalks, above the Vaals clays. Here, only a small aquifer is contained in the Aachen sands, fed in the areas where the sands crop out and resting on the impervious, weathered-to-clay shales. Present-day yearly rainfall is of $900 \mathrm{~mm}$ with two peaks in June-August and November-January (Fig. 3B).

Detailed field investigations, performed to unravel the mechanism of the landslide reactivation, have pointed out the probable role played by the sewage pipe crossing the landslide (Demoulin and Glade, 2004).

\section{Methodology}

Complemented with field observation of the evolution of morphological features such as the headscarp, scarplets within the slipped mass and ground fissures (Fig. 2C), the monitoring of the landslide displacements was performed by repeated GPS surveys (Table 1). A first set of 14 marks covering the southern half of the landslide (Fig. 2A) was repeatedly measured in 1999-2000. Measure- ments were then carried out in 2001 2002 for 30 marks installed in the northern half of the slide, together with further measurements of four marks retrieved from the first network. A last survey of a limited set of remaining marks took place in June 2005. For each network, an assumed fixed reference frame was comprised of at least three marks located out of the slide and encompassing it. One of these marks belonged to both sets and allowed their connection. The measurements were carried out in rapid static mode with Leica SR95OO dualfrequency receivers. Dealing with baselines shorter than $0.25 \mathrm{~km}, 120$ epoch-long data series were enough to solve all ambiguities, the field conditions and the data processing jointly accounting for an uncertainty of $\sim 2 \mathrm{~cm}$ in all three components $(\mathrm{N}, \mathrm{E}$ and $\mathrm{Up}$ ) of relative positioning, i.e. an uncertainty of $\sim 3 \mathrm{~cm}$ in the components of relative motion.

In order to gain a longer-term insight into the displacement history, I compared the precise DEMs of the landslide topography at epochs separ- ated by $\sim 50$ years. The first DEM was produced by digital stereophotogrammetry from aerial photographs of 1953 and was compared with another one interpolated from a GPS survey of the landslide performed in 1999.

For 1953, the negatives of photographs at the 1:15000 scale were scanned at a pixel resolution of $12.5 \mu \mathrm{m}$ corresponding to a ground resolution of $\sim 0.2 \mathrm{~m}$. The camera parameters determined by the geometric calibration and the fiducial marks figured on each photo were used to realize the internal orientation (Dewitte and Demoulin, 2005). To estimate the accuracy of the stereomodels in relative orientation, owing to the rather poor identification of the measured points in a monotonous grass cover, I applied the following semiempirical formulas (Kraus, 1993)

$$
\begin{aligned}
& (\mathrm{RMS})_{x y}=0.03 e_{\mathrm{c}} \text { and } \\
& (\mathrm{RMS})_{z}=0.015\left(\frac{f}{b}\right) e_{\mathrm{c}}
\end{aligned}
$$

with $e_{\mathrm{c}}=$ inverse of the photo scale, $f=$ focal length $=114.56 \mathrm{~mm}$ and 


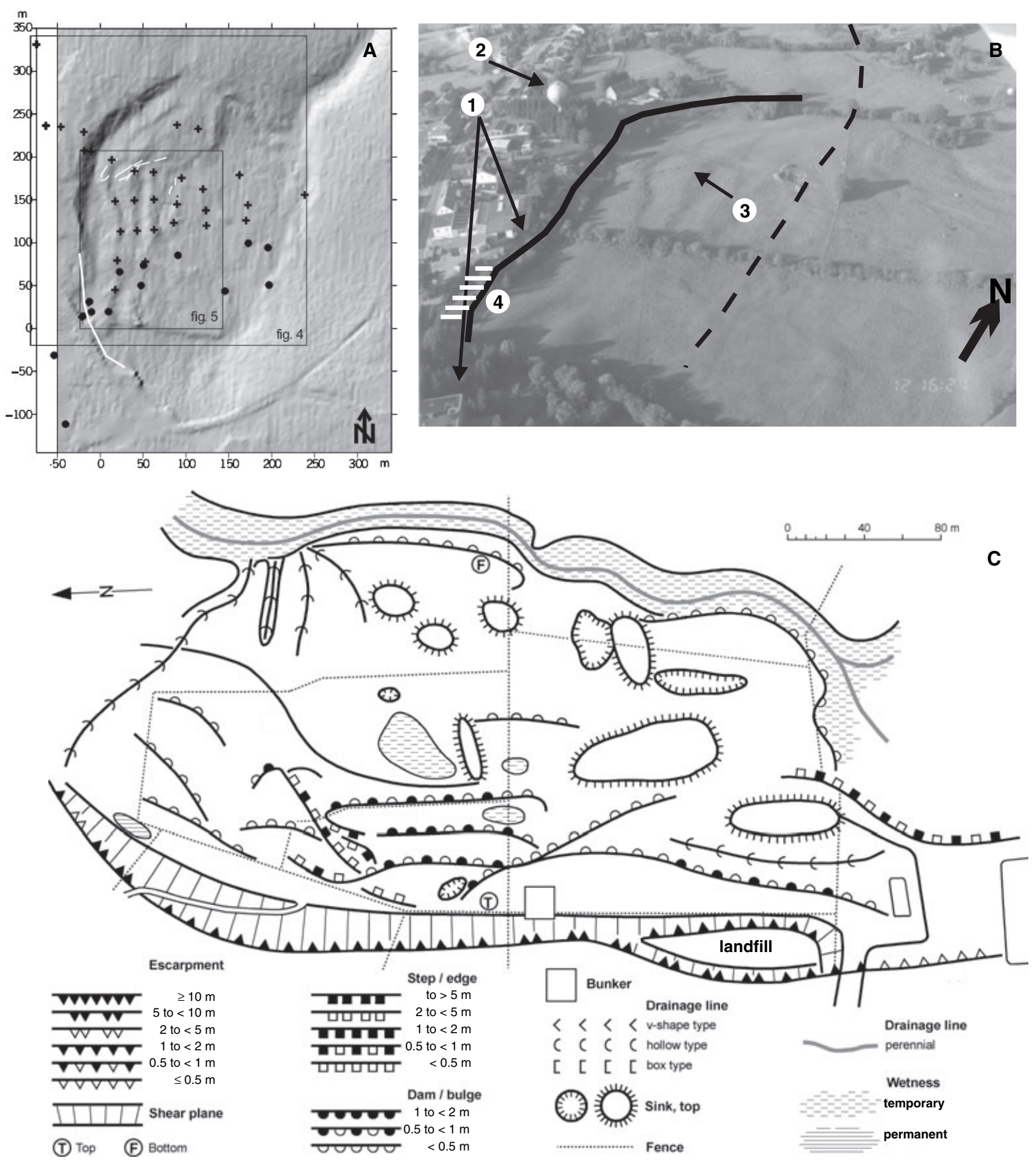

Fig. 2 (A) Close-up of the Manaihan landslide in the DEM of 1953, showing the distribution of the two sets of GPS marks (respectively, solid circles and crosses). Bold white lines delineate the reactivated southern part of the headscarp and the fractures associated with the graben developed to the north in September 1998. (B) Oblique aerial photograph of the landslide during the spring 2000, locating various features mentioned in the text. The comparison with (A) shows that no fundamental difference exists in the geomorphology of the landslide between the two epochs, except the sharpening and downslope displacement of the transverse ridges locating the edges of the rotated blocks. (1) At least two buildings were severely damaged in the September 1998 event, while (2) a water tower is located very close to the scarp. (3) The northern limit of the reactivated part of the landslide is marked by a small graben. (4) The landfill located along the southern part of the scarp was placed there in the 1970s to build a house, which rapidly suffered severe tilt and was abandoned in the 1980s. (C) Geomorphological map of the Manaihan landslide (after Demoulin and Glade, 2004 - map compiled by T. Glade). 


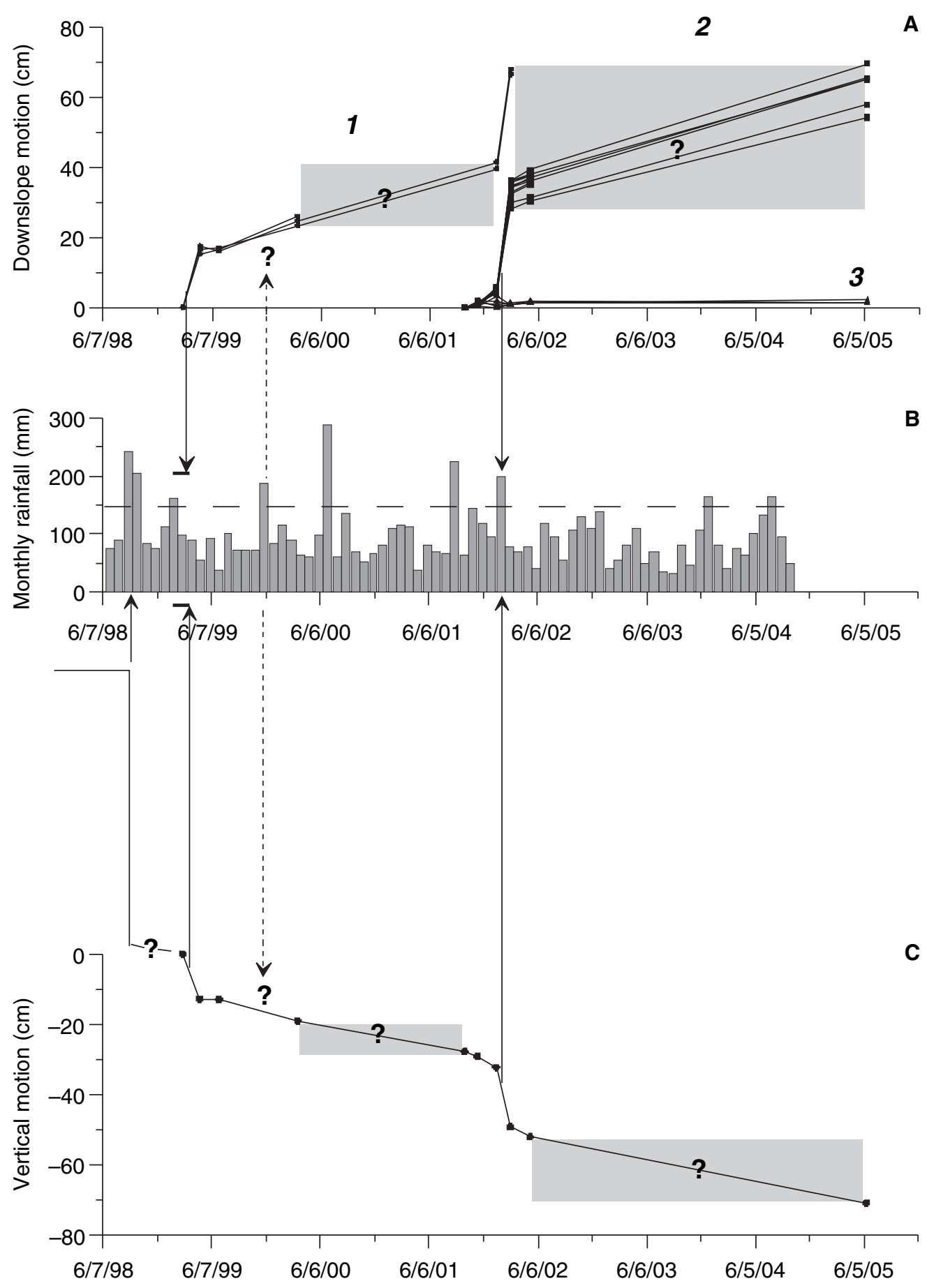

Fig. 3 Relation between measured landslide displacements and rainfall. (A) Downslope motions recorded for the southern set of

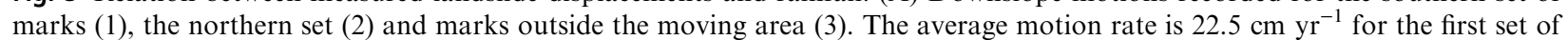
marks (1999-2002) and $18.9 \mathrm{~cm} \mathrm{yr}^{-1}$ for the second (2001-2005). The grey rectangles delimit the uncertainty area of motion evolution for time intervals exceeding 1 year. The date format ( $x$-axis) is $\mathrm{m} / \mathrm{d} / \mathrm{yy}$. (B) Monthly rainfall histogram. The dashed horizontal threshold line tentatively placed at $150 \mathrm{~mm}$ monthly rainfall highlights the rainfall events which might have triggered slope movements. (C) Vertical motion at the southern part of the headscarp. The solid arrows relate observed motion and rainfall events. The dashed arrows show that the high rainfall amount of December $1999(187 \mathrm{~mm})$ induced surprisingly small motion.

$b=$ distance between the optical centres of the photos $=60 \mathrm{~mm}$, which yielded RMS errors of $45 \mathrm{~cm}$ in $x$ and $y$ and $43 \mathrm{~cm}$ in $z$. These are mean uncertainty values for the coordinates of individual points. However, the actual quality of the stereophotogrammetric model also depends on the density of the measured points. The 
Table 1 Summary of the GPS surveys carried out from 1999 to 2005.

\begin{tabular}{|c|c|c|c|}
\hline & $\begin{array}{l}\text { Type of } \\
\text { survey }\end{array}$ & Network & Technical characteristics \\
\hline 01/03/1999 & Rapid static DGPS & 14 points - southern network & $\begin{array}{l}120 \text { measurements/point, measurement } \\
\text { frequency: } 1 / 6 \mathrm{~s}^{-1}\end{array}$ \\
\hline 27/04/1999 & Rapid static DGPS & Idem & Idem \\
\hline 01/07/1999 & Rapid static DGPS & 13 points - southern network & Idem \\
\hline$-/ 07 / 1999$ & Kinematic DGPS & $\begin{array}{l}\sim 12000 \text { points covering the } \\
\text { whole landslide }\end{array}$ & $\begin{array}{l}\text { Point of initialization: } 120 \text { measurements; } \\
\text { others: } 1 \text { measurement, measurement } \\
\text { frequency: } 1 \mathrm{~s}^{-1}\end{array}$ \\
\hline $21 / 03 / 2000$ & Rapid static DGPS & 13 points - southern network & $\begin{array}{l}120 \text { measurements/point, measurement } \\
\text { frequency: } 1 / 6 \mathrm{~s}^{-1}\end{array}$ \\
\hline $02 / 10 / 2001$ & Rapid static DGPS & $\begin{array}{l}30 \text { points }- \text { northern network } \\
+2 \text { points - southern network }\end{array}$ & $\begin{array}{l}120 \text { measurements/point, measurement } \\
\text { frequency: } 1 / 6 s^{-1}(+ \text { inclinometry })\end{array}$ \\
\hline $15 / 11 / 2001$ & Rapid static DGPS & Idem & Idem \\
\hline $17 / 01 / 2002$ & Rapid static DGPS & $\begin{array}{l}30 \text { points - northern network } \\
+4 \text { points - southern network }\end{array}$ & Idem \\
\hline 05/03/2002 & Rapid static DGPS & Idem & Idem \\
\hline $10 / 05 / 2002$ & Rapid static DGPS & $\begin{array}{l}27 \text { points - northern network } \\
+2 \text { points - southern network }\end{array}$ & Idem \\
\hline $13 / 06 / 2005$ & Rapid static DGPS & $\begin{array}{l}15 \text { points - northern network } \\
+2 \text { points - southern network }\end{array}$ & $\begin{array}{l}120 \text { measurements/point, measurement } \\
\text { frequency: } 1 / 6 \mathrm{~s}^{-1}\end{array}$ \\
\hline
\end{tabular}

mean density is here 0.06 point $\mathrm{m}^{-2}$ (one point every $4 \mathrm{~m}$ ), but it is much higher in the areas of more contrasted topography, in particular within the landslide. An a posteriori estimate of the model uncertainty could be obtained from a comparison with the GPS-derived topographic model in the non moving areas surrounding the landslide. This suggests a relative error in $z$ of $\sim 20 \mathrm{~cm}$ for the 1953 model.

Since no recent aerial photographs were available, I surveyed in differential GPS (DGPS) kinematic mode an area of $\sim 165 \times 210 \mathrm{~m}^{2}$ encompassing the reactivated part of the Manaihan landslide during the summer 1999. The great advantage of this survey mode is the measurement of a huge number of points in a limited time. I measured 12000 points, with a mean density of 0.4 point $\mathrm{m}^{-2}$ similar to that of the derived interpolation grid. In order to avoid any unsolved ambiguity in the data processing, that would have led to unreliable solutions for parts of the survey, special attention was paid to reinitializing the rover receiver after every cycle slip during the kinematic survey. Consequently, the internal uncertainty on the up component of the model is estimated between 5 and $10 \mathrm{~cm}$. Much more than by the data processing, it was determined by the field conditions, in particular the difficulty to

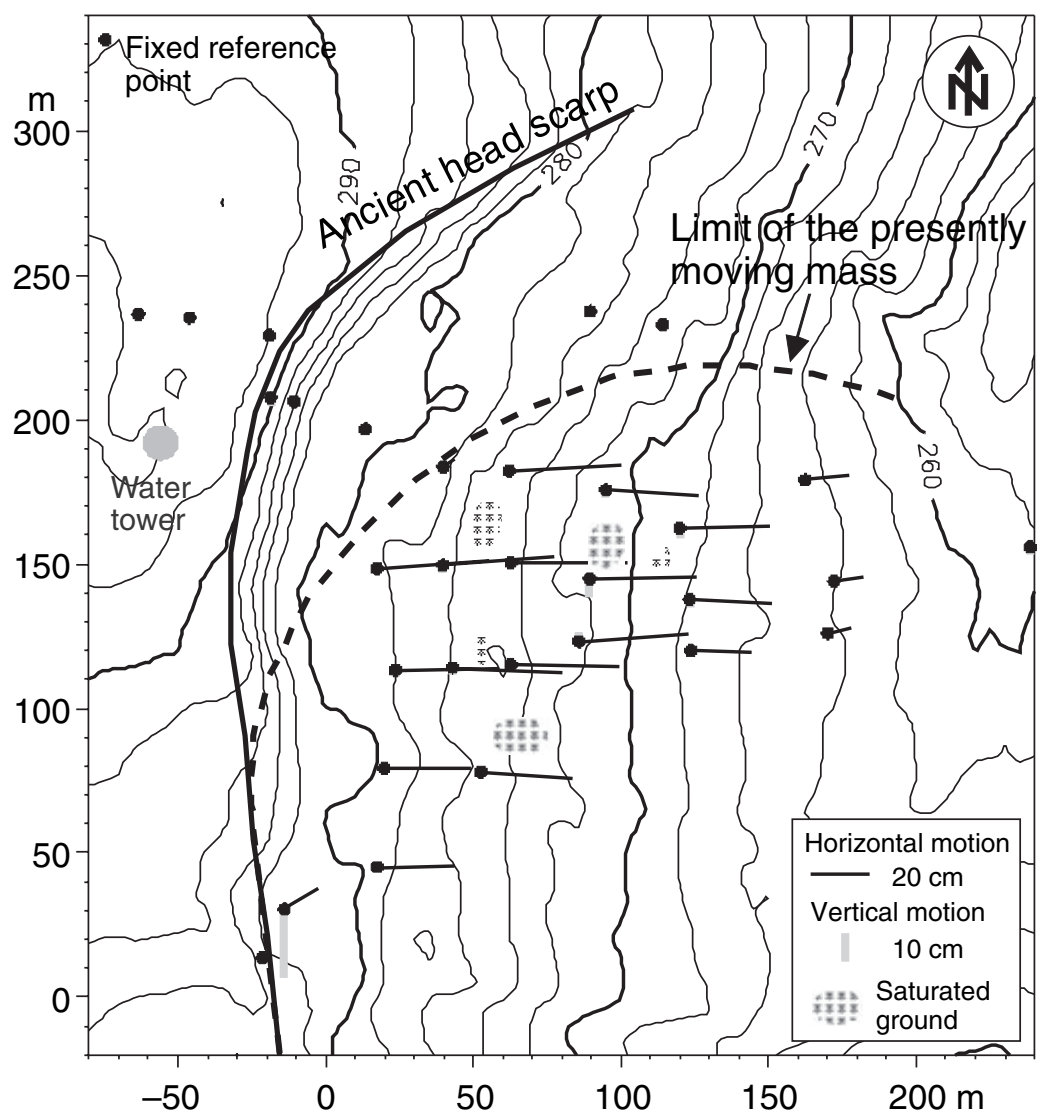

Fig. 4 Map of downslope ( $\sim$ horizontal) and vertical motions recorded by repeated GPS surveys of the second set of marks during the period from 2 October 2001 to 10 May 2002. The northern boundary of the currently reactivated area is clearly delineated. Most patches of marshy ground are resulting from groundwater emergence in the back tilted blocks. 


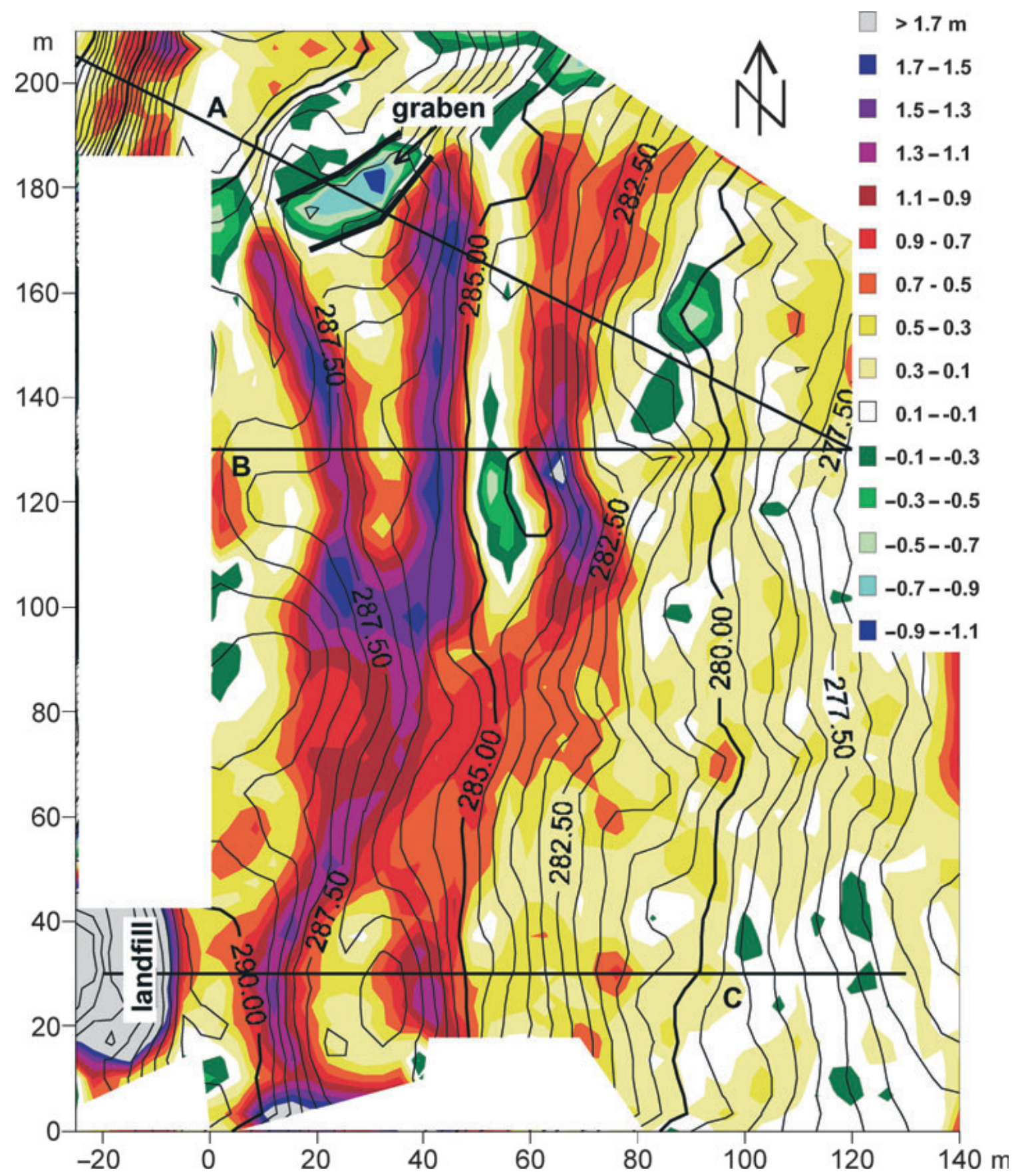

Fig. 5 Map of the vertical ground displacements inferred from the comparison between DEMs of 1953 and 1999. The underlying contour lines describe the topography of 1999, showing that the zones of highest 'uplift' correspond to the current location of ridges and result from their downslope displacement. Lettered black lines locate the profiles of Fig. 6. The blank areas correspond to zones of no GPS data. Unfortunately, they encompass most of the headscarp, where the combination of steep slopes, very irregular ground and dense shrubs made a kinematic GPS survey impossible. The strong apparent uplift in the SW corner of the map corresponds to the embankment of a house built in the 1970s, now destroyed. The NE-striking zone of subsidence in the NW corner delimits the small graben appeared during the slip event of September 1998.

keep holding the staff supporting the antenna vertical and in contact with the ground during its displacement over the sods.
Finally, the 1953 DEM was referenced to that of 1999 by measuring common points in both epochs. Owing to the elapsed time span and the change in many landscape details, the scale of the photographs, and the satellite visibility required for GPS measurement, I found only three reli- 
able control points to compute the parameters of the Helmert transformation. The quality of the transformation is strongly dependent on the identification of these points on the photographs, performed with an accuracy better than $50 \mathrm{~cm}$ in $x$ and $y$ and of $\sim 5 \mathrm{~cm}$ in $z$. After common referencing, the model of 1953 was subtracted from that of 1999 to map the changes in $z$. The error of the final map of $z$ change is $<70 \mathrm{~cm}$ in ground plan and $\sim 25 \mathrm{~cm}$ in height variation.

\section{Results}

\section{8-2005 displacements}

The more than centennial daily rainfall of 14 September 1998 (126 mm) caused a sudden displacement of the Manaihan landslide, materialized by the development of a new $0.8 \mathrm{~m}$-high, $70 \mathrm{~m}$-long scarplet along the southern part of its headscarp and by the subsidence of a small graben along the northern margin of the reactivated zone (Fig. 2).

After this event, the slide continued to move episodically. The two most prominent slip episodes were recorded in the end of the 1998-1999 and 20012002 winters, respectively with 15$18 \mathrm{~cm}$ downslope motion of several marks of the southern network and $26-31 \mathrm{~cm}$ displacements in the most active part of the northern network (Fig. 3). The repeated surveys spanning these periods suggest that such motion occurs within few days, or even hours as indicated by the significant widening of ground fissures and the reactivation of the 1998 scarp over one night in March 1999. While I recorded a maximum $40 \mathrm{~cm}$ ground displacement for the main moving mass during the winter 2001-2002, the total downslope motion did not exceed $70 \mathrm{~cm}$ over a 3- or 4-year period (respectively, 1999-2002 for the first set of benchmarks, 20012005 for the second). As a consequence of the downslope movement of the landslide, the blocks located immediately below the newly formed headscarp suffered a $71 \mathrm{~cm}$ subsidence from 1998 to 2005, of which $10 \mathrm{~cm}$ in March-April 1999 and $17 \mathrm{~cm}$ in January-February 2002. When available, inclinometer measurements showed displacement rates at depth similar to those observed at the ground surface
(Demoulin and Glade, 2004), indicating en-bloc motion of the slipping mass.

Not the whole landslide is currently moving. Its northern part, separated from the central mass by overstepping scarplets and the small graben developed in September 1998 oblique to the headscarp, has not been reactivated (Fig. 4). In this area, the old headscarp shows no significant displacement either. To the south of this limit, the landslide moves downslope as a whole, with highest amounts of motion in its upslope half progressively decreasing towards the valley bottom. Only minor vertical displacements are observed within the landslide. By contrast, the southern part of the headscarp is clearly rejuvenated, the height

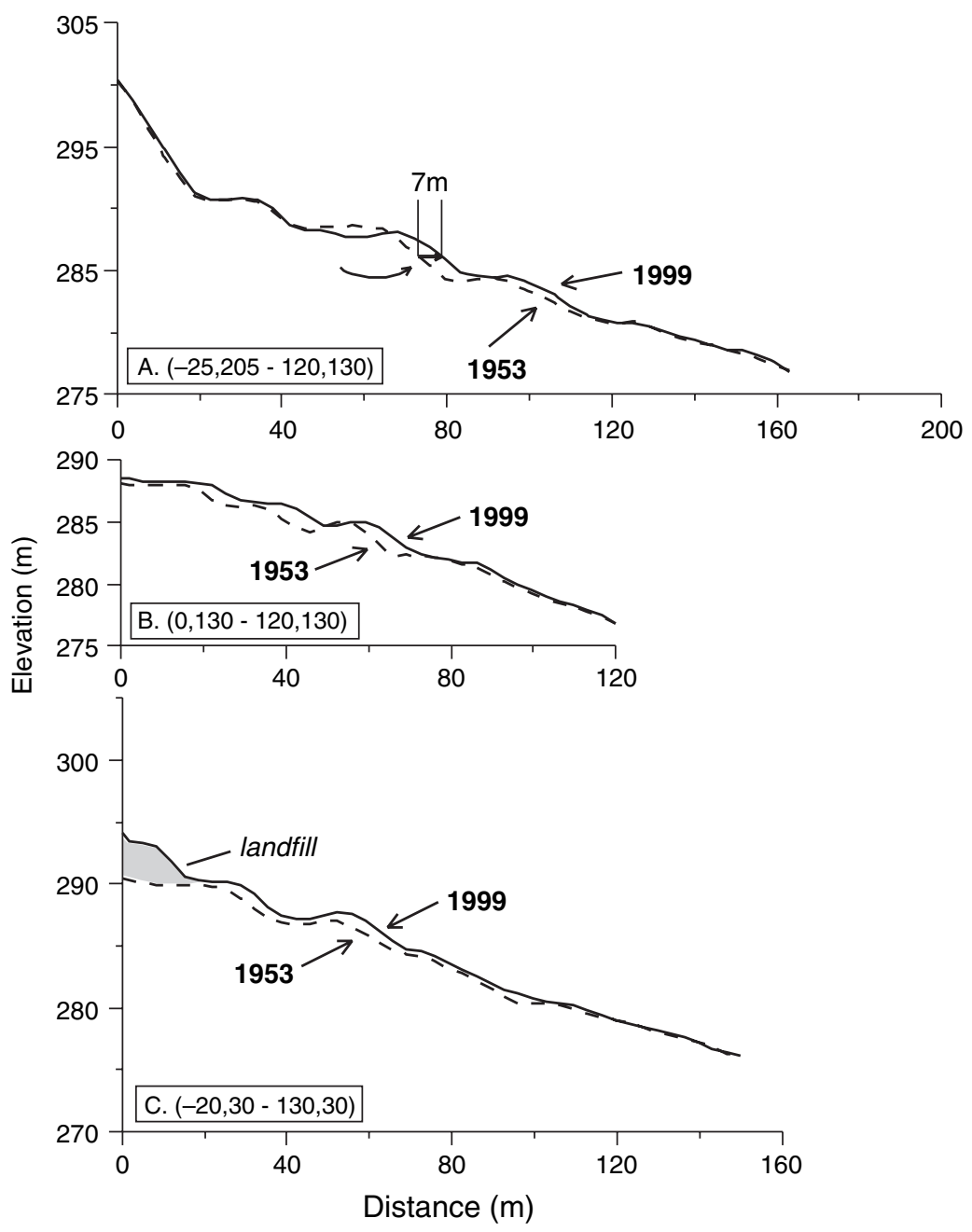

Fig. 6 Topographical profiles across the landslide, illustrating the 1953-1999 lateral motion of ridges. The boxes in the lower left corner of the profiles give the $(x, y)$ coordinates of their start- and endpoints on the map of Fig. 5. 
downslope displacement of $\sim 2 \mathrm{~m}$ high ridges corresponding to the uplifted edge of tilted blocks (Fig. 6). In the central part of the landslide, this displacement amounts to 6-7 $\mathrm{m}$ and it decreases to $\sim 4 \mathrm{~m}$ near the lateral margins of the reactivated area. The current landslide motion is thus mainly translational above the distal part of the surface of rupture, involving void creation and block subsidence at the foot of the scarp, with a minor component of rotation which sharpens the ridges.

\section{Discussion}

All short- and long-term measurements are consistent with an average downslope motion rate in the range $15-25 \mathrm{~cm} \mathrm{yr}^{-1}$. This is obvious from the GPS surveys of the period 19982005 (Fig. 3). By contrast, the figure derived from the 1953-1999 comparison results from a more complex history. Several eye-witnesses have consistently stated that the landslide was dormant until $\sim 1980$, suggesting that the displacement evidenced by this comparison actually occurred in a $\sim 20$-year long time span (1980-1999). Moreover, the recorded motion includes the event of September 1998 with an unknown amplitude of downslope displacement. I estimate this amplitude from the ratio $d_{\mathrm{h}} / d_{\mathrm{v}}$ between the downslope displacement of the landslide and the simultaneous vertical slip on the headscarp at several epochs since 1998. With $d_{\mathrm{h}} / d_{\mathrm{v}} \approx$ 1.4 and a headscarp slip of $\sim 1 \mathrm{~m}$ on 14 September 1998, the concomitant downslope displacement was $\sim 1.4 \mathrm{~m}$. The extension deduced from the geometry of the small graben appeared at that time along the northern margin of the reactivated mass yields a similar value of $\sim 1.5 \mathrm{~m}$. One must add to this figure a few decimetres of unusual displacement occurring between September 1998 and my first GPS measurements of 1 March 1999, and causing $40 \mathrm{~cm}$-wide fissure opening along the headscarp. This leaves $\sim 4-5 \mathrm{~m}$ of motion during the 19801999 time interval, i.e. a mean rate of 20-25 $\mathrm{cm} \mathrm{yr}^{-1}$ consistent with that deduced from the GPS data.

There are unfortunately long gaps in the time series of the landslide movements. However, with the exception of the catastrophic event of
September 1998, all important displacements have been observed around the winter's end, in February and March. Moreover, the two periods of observed increased motion responded to anomalously high rainfall amounts during the preceding weeks, respectively 162.4 and $198.7 \mathrm{~mm}$ in February 1999 and 2002 (Fig. 3). By contrast, the GPS measurements do not reveal any significant motion during the springs of 1999 and 2002 and the autumn and first half of winter 2001, and several wet summer months (e.g. $287.6 \mathrm{~mm}$ in July 2000 and $226.7 \mathrm{~mm}$ in September 2001) had apparently little influence on the landslide. Indeed, no matter how the curves are interpolated (Fig. 3), the amount of displacement that could be ascribed to these wet summer months remains by far short of what would be expected from the corresponding rainfall. This results probably from the intense evaporation associated with summer rainfall, thus reducing the amount of percolating water, and from the absence of very intense daily rainfall. There is therefore a clear tendency towards seasonal activation of the landslide, the end of the winter being most favourable to the combined occurrence of long-lasting precipitation, minimal evaporation, and anomalously high daily rainfall, triggering decimetre-scale displacement of the slide.

Spatially, the displacements recorded since September 1998 point to a reactivation limited to the southern part of the landslide, with a southward development of the headscarp (Fig. 4). Moreover, in March 1999, the ground collapsed in the places where the borders of the reactivated area intersects the sewage pipe crossing the landslide, suggesting that the reactivated area closely coincides with the zone of broken pipe. This shows that, even if particular episodes of intense rainfall are responsible for triggering displacements, the underlying actual cause of the reactivation is the continuous seepage from the pipe maintaining local high pore pressures, which substantially reduce the shear strength of the landslide.

\section{Conclusion}

The combination of methods applied to monitor the displacements of the
Manaihan landslide over weeks to decades yielded consistent results. GPS kinematic surveying proved efficient in providing a detailed and accurate topographic model. At least in open terrane, it should be considered complementary with precise point positioning in ground displacement monitoring. Stereophotogrammetry of historical aerial photographs is an indispensable data source for extending rate estimates over longer time spans.

Current landslide motion at Manaihan is mainly translational. Beyond the September 1998 event, it occurs at a mean rate of $c .20 \mathrm{~cm} \mathrm{yr}^{-1}$ corresponding to a seasonal activity centred on the winter's end. This activity is caused by seepage from a pipe within the landslide, which locally reduces the shear stress required to initiate slip in response to periods of intense rainfall and percolation.

\section{Acknowledgements}

I gratefully acknowledge the help of A. Collignon and J.C. Jasselette, who performed the stereophotogrammetric analysis. R. Billen and B. Schumacker calculated the transformation between the DEMs.

\section{References}

Berardino, P., Costantini, M., Franceschetti, G., Iodice, A., Pietranera, L. and Rizzo, V., 2003. Use of differential SAR interferometry in monitoring and modelling large slope instability at Maratea (Basilicata, Italy). Eng. Geol., 68, 31-51. Chandler, J. and Brunsden, D., 1995.

Steady state behaviour of the Black Ven mudslide: the application of archival analytical photogrammetry to studies of landform change. Earth Surf. Proc. Landf., 20, 255-275.

Coe, J., Ellis, W., Godt, J., Savage, W., Savage, J., Michael, J., Kibler, J., Powers, P., Lidke, D. and Debray, S., 2003. Seasonal movement of the Slumgullion landslide determined from Global Positioning System surveys and field instrumentation, July 1998-March 2002. Eng. Geol., 68, 67-101.

Demoulin, A. and Glade, T., 2004. Recent landslide activity in Manaihan, E Belgium. Landslides, 1, 305-310.

Demoulin, A., Pissart, A. and Schroeder, C., 2003. On the origin of late Quaternary palaeolandslides in the Liège (E Belgium) area. Int. J. Earth Sci. (Geol. Rdsch.), 92, 795-805.

Dewitte, O. and Demoulin, A., 2005. Morphometry and kinematics of land- 
slides inferred from precise DTMs in

West Belgium. Nat. Hazards Earth Syst. Sci., 5, 259-265.

Gili, J., Corominas, J. and Rius, J., 2000. Using Global Positioning System techniques in landslide monitoring. Eng. Geol., 55, 167-192.

Hapke, C., 2005. Estimation of regional material yield from coastal landslides based on historical digital terrain modelling. Earth Surf. Proc. Landf., 3, 679-697.

Kerle, N., 2002. Volume estimation of the 1998 flank collapse at Casita volcano, Nicaragua: a comparison of photogrammetric and conventional techniques. Earth Surf. Proc. Landf., 27, 759-772.

Kraus, K., 1993. Photogrammetry. Vol. 1. Fundamentals and Standard Processes, 4th edn. Dümmler Verlag, Bonn, 397 pp.
Lantuit, H. and Pollard, W., 2005. Temporal stereophotogrammetric analysis of retrogressive thaw slumps on Herschel Island, Yukon Territory. Nat. Hazards Earth Syst. Sci., 5, 413-423.

Malet, J.P., Maquaire, O. and Calais, E., 2002. The use of Global Positioning System techniques for the continuous monitoring of landslides: application to the Super-Sauze earthflow

(Alpes-de-Haute-Provence, France). Geomorphology, 43, 33-54.

Moss, J., 2000. Using the Global Positioning System to monitor dynamic ground deformation networks on potentially active landslides. Int. J. Appl. Earth Observ. Geoinf., 2, 24-32.

Skempton A. and Hutchinson J., 1969. Stability of natural slopes and embankment foundations. In: Proceedings of the 7th International Conference on Soil Mechanics and Foundation Engineering, Soc. Mexic. Mec. Suelos, Mexico, pp. 291-340.

Squarzoni, C., Delacourt, T. and Allemand, P., 2003. Nine years of spatial and temporal evolution of the La Valette landslide observed by SAR interferometry. Eng. Geol., 68, 53-66.

Squarzoni, C., Delacourt, T. and Allemand, P., 2005. Differential singlefrequency GPS monitoring of the La Valette landslide (French Alps). Eng. Geol., 79, 215-229.

Received 7 October 2005; revised version accepted 3 June 2006 